\title{
Toxicity and Cell Cycle Effects of Synthetic 8-Prenylnaringenin and Derivatives in Human Cells
}

\author{
Sergey V. Tokalova ${ }^{a}$ vonne Henker ${ }^{a}$ Pia Schwab $^{b}$ Peter Metz ${ }^{b}$ \\ Herwig O. Gutzeit ${ }^{a}$
}

a Institut für Zoologie, and 'Institut für Organische Chemie, TU Dresden, Dresden, Germany

\section{Key Words}

8-Prenylnaringenin · Cell cycle · Toxicity · Apoptosis · Mitochondrial membrane potential

\begin{abstract}
The estrogenic flavanone rac-8-prenylnaringenin (8-PN) and 3 derivatives ( rac-7-(O-prenyl)naringenin-4'-acetate (7-O-PN), rac-5-(O-prenyl)naringenin-4',7-diacetate (5-OPN), and rac-6-(1,1-dimethylallyl)naringenin (6-DMAN) were prepared by chemical synthesis and analyzed with respect to their toxicity and possible cell cycle effects in human acute myeloid leukemia (HL-60) cells. With the exception of 5-O-PN, all the other naringenins showed only weak toxic effects at concentrations below 50 $\mu \mathrm{mol} / \mathrm{l}$. A cell cycle analysis over several cell generations up to 4 days was carried out using the fluorescent dye carboxyfluorescein diacetate $\mathrm{N}$-succinimidyl ester (CFSE) followed by propidium iodide (PI) staining at the end of the experiment. The well-studied flavonol quercetin was included in the analysis as a reference substance. All flavonoids affected cell proliferation, but the extent and the resulting changes in the proliferation pattern were specific for each substance. In contrast to the radical scavenging activity of quercetin, the tested flava-
\end{abstract}

\section{KARGER}

Fax +41613061234 E-Mail karger@karger.ch www. karger.com
(C) 2004 S. Karger AG, Basel

0031-7012/04/0711-0046\$21.00/0

Accessible online at:

www. karger.com/pha nones showed no anti-oxidative properties using several different test systems. Similarly, the mitochondrial membrane potential $(\Delta \Psi \mathrm{m})$ was hardly effected by these compounds, while both menadione and quercetin strongly reduced the potential after $1 \mathrm{~h}$ of treatment. The reported chemical modification of interesting lead substances (like the strongly estrogenic 8-PN) presents a promising approach to modulate the properties of a relevant substance in a pharmacologically desirable way. The low toxicity and weak cytostatic properties of the tested naringenin derivatives is encouraging for further studies on known naringenin target molecules.

Copyright $\odot 2004$ S. Karger AG, Basel

\section{Introduction}

The prenylated flavanone 8-prenylnaringenin (8-PN) has been shown to be highly estrogenic $[1,2]$ and acts as an agonist of the human estrogen receptor. The substance is present in the flowers of hops (Humulus lupulus L.) and its estrogenic activity is thought to be responsible for menstrual disturbances of female workers picking hops by hand [3]. The substance isolated from hops was shown to contain similar amounts of both (R)- and (S)-enantiomers 
and showed similar binding characteristics to both $\alpha$ - and $\beta$-estrogen receptor isoforms [1]. 8-PN and three other related flavanones were synthesized in high purity $(>99 \%)$ as described in part before, and the biological activity of 8-PN with respect to estrogenicity has been confirmed [2, 4]. Because of the potential pharmacological use of 8-PN and derivatives, the biological properties of these compounds are of interest. In addition, it was our aim to demonstrate that flavanones can be synthesized chemically with high efficiency and good yield thus making future pharmacological experiments more attractive.

While the estrogenic activity of 8-PN has been addressed by several authors, other biological effects have not been studied in detail. It has become increasingly clear from a number of studies with different flavonoids that substitutions in the $\mathrm{A}, \mathrm{B}$, or $\mathrm{C}$ ring (fig. 1a) may profoundly affect the biological activity. Prenylation is a case in point and may result in stronger or altered activity concerning cell proliferation in different cancer cell lines [5] or the inhibition of the human P450 enzyme CYP1A2 [6]. Other minor structural changes in flavonoids may strongly affect the biological activity of the target molecules, for example, enzymes or receptor molecules. Flavonoids and their known targets are well suited to analyze functional correlations between the chemical structure and the functional consequences. For example, some flavanones (including naringenin) and isoflavones inhibit aromatase. By site-directed mutagenesis of the gene coding for aromatase, structural properties pertinent to the specific function could be described [7]. Structural features also determine the strong scavenger activity for reactive oxygen species (ROS) of some flavonoids [8-10]. Quercetin has a strong scavenging potency $[11,12]$ and for this reason we have used quercetin as a reference flavonoid in an analysis of the antioxidative potency of the naringenin derivatives that are the subject of this study. The ability of quercetin and many flavonoids to act as scavengers for ROS is thought to be a major reason for the beneficial effects of dietary flavonoids.

The cell cycle is a highly controlled process and easily disrupted when cellular functions become disturbed by xenobiotics or under conditions of stress. For this reason, cell cycle analysis is a sensitive test for the toxicity of test compounds. In the case of quercetin and genistein a phase-specific inhibition of the cell cycle has been reported and these cytostatic properties have been of pharmacological interest. In human OCM-1 melanoma cells the presence of a hydroxyl group at the $3^{\prime}$ position of the ring $\mathrm{B}$ in quercetin and luteolin was shown to correlate with cell cycle arrest in $G_{1}$, while its absence in kaempfer-

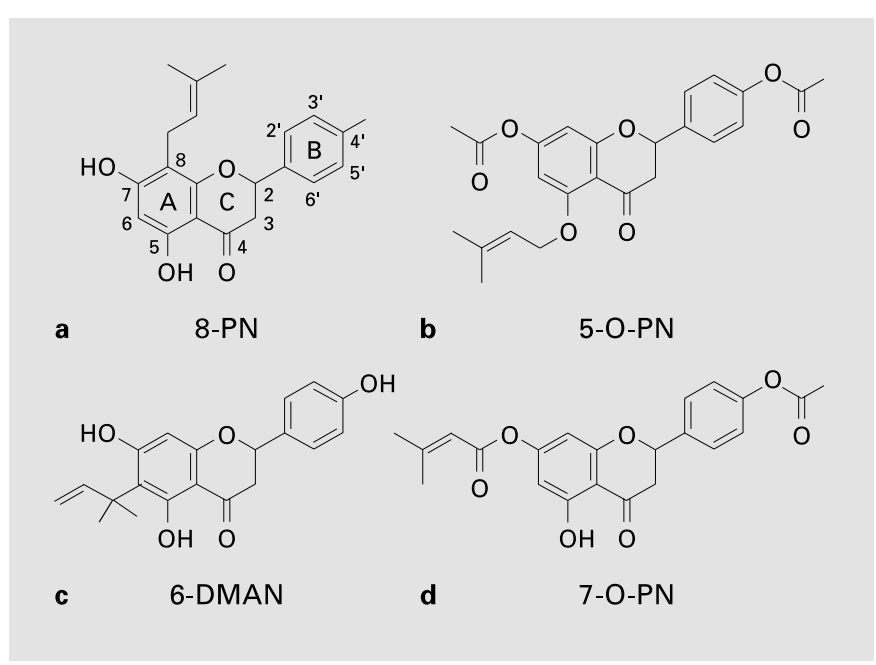

Fig. 1. Chemical structures of the analyzed flavonoids. 8-PN $=\mathrm{rac}-$ 8-prenylnaringenin (a); 5-O-PN = rac-5-(O-prenyl)naringenin-4' ${ }^{\prime}$ 7diacetate (b); 6-DMAN = rac-6-(1,1-dimethylallyl)naringenin (c); 7$\mathrm{O}-\mathrm{PN}=$ rac-7-(O-prenyl)naringenin-4'-acetate $(\mathbf{d})$.

ol and apigenin correlated with a $\mathrm{G}_{2}$ block. Genistein with a hydroxyl at position 5 of ring $A$ arrested cells in $G_{2}$, while daidzein which lacks this group induced an accumulation of cells in $G_{1}$ [13]. Antiproliferative activities were commonly observed when studying the biological effects of flavonoids [14]. In these and many other in vitro studies, the flavonoid concentrations were high and often exceeded $100 \mu \mathrm{mol} / \mathrm{l}$. Such concentrations are clearly not physiological and must be interpreted with caution. For this reason, we have used concentrations below $100 \mu \mathrm{mol} / 1$ in all experiments of this study.

Another sensitive and quite different indicator for cell toxicity is the induced reduction in the mitochondrial inner transmembrane potential $(\Delta \Psi \mathrm{m})$. Recently, mitochondria have been shown to play a key role in apoptosis through the release of cytochrome $\mathrm{c}$ in response to many anticancer drugs and cellular stress $[15,16]$. In many apoptotic pathways, the mitochondrial transmembrane potential collapses [17], indicating the opening of the socalled mitochondrial permeability transition pore. Even when a temporary reduction in the transmembrane potential does not result in apoptosis the effect on the potentialdependent proton pump will lead to decreased ATP production $[18,19]$. In this study we examined the effects of the flavonoids on the mitochondrial membrane potential using the fluorescent potential-sensitive dye JC-1. 


\section{Materials and Methods}

\section{Chemistry}

The following substances were used in this study (fig. 1): rac-7(O-prenyl)naringenin-4'-acetate (abbreviated 7-O-PN), rac-5-(Oprenyl)naringenin-4',7-diacetate (5-O-PN), rac-8-prenylnaringenin (8-PN), and rac-6-(1,1-dimethylallyl)naringenin (6-DMAN). The preparation of 5-O-PN, 8-PN and 6-DMAN in high purity (>99\%) was described in detail previously [4], while 7-O-PN was obtained as a minor byproduct during the preparation of $\mathrm{rac}-5-(\mathrm{O}-$ prenyl)naringenin-4', 7-diacetate (5-O-PN) from rac-naringenin-4',7-diacetate [4]. Separation of the crude product mixture by flash chromatography (ethyl acetate/pentane, 1:2) followed by recrystallization from a diethyl ether/pentane mixture gave pure 7-O-PN (9\% chemical yield, $>99 \%$ purity) as a white solid. The presence of the prenyloxy substituent at $\mathrm{C}(7)$ was confirmed by detailed 2D NMR experiments (COSY, NOESY, HMBC, HSQC).

Data of 7-O-PN: $R_{f} 0.75$ (ethyl acetate/pentane, 1:2); m.p. 81$82^{\circ} \mathrm{C}$ (diethyl ether/pentane); IR (KBr): 3,437, 3,063, 2,980, 2,919, $1,743,1,647,1,577,1,511,1,445,1,375,1,301,1,277,1,232,1,201$, $1,159,1,090 \mathrm{~cm}^{-1} ;{ }^{1} \mathrm{H} \mathrm{NMR}\left(\mathrm{CDCl}_{3}, 500 \mathrm{MHz}\right): \delta 1.72(\mathrm{~s}, 3 \mathrm{H}), 1.78$ $(\mathrm{s}, 3 \mathrm{H}), 2.31(\mathrm{~s}, 3 \mathrm{H}), 2.80(\mathrm{dd}, 1 \mathrm{H}, J=17.1 \mathrm{~Hz}, J=3.0 \mathrm{~Hz}), 3.05(\mathrm{dd}$, $1 \mathrm{H}, J=17.1 \mathrm{~Hz}, J=13.0 \mathrm{~Hz}), 4.51(\mathrm{~d}, 2 \mathrm{H}, J=6.7 \mathrm{~Hz}), 5.41(\mathrm{dd}, 1 \mathrm{H}$, $J=13.0 \mathrm{~Hz}, J=3.0 \mathrm{~Hz}), 5.44(\mathrm{t}, 1 \mathrm{H}, J=6.7 \mathrm{~Hz}), 6.04(\mathrm{~d}, 1 \mathrm{H}, J=2.3$ $\mathrm{Hz}), 6.07(\mathrm{~d}, 1 \mathrm{H}, J=2.3 \mathrm{~Hz}), 7.15(\mathrm{~d}, 2 \mathrm{H}, J=8.5 \mathrm{~Hz}), 7.46(\mathrm{~d}, 2 \mathrm{H}$, $J=8.5 \mathrm{~Hz}), 11.98(\mathrm{~s}, 1 \mathrm{H}) ;{ }^{13} \mathrm{C} \mathrm{NMR}\left(\mathrm{CDCl}_{3}, 125 \mathrm{MHz}\right): \delta 18.22(\mathrm{q})$, $21.11(\mathrm{q}), 25.79(\mathrm{q}), 43.36(\mathrm{t}), 65.32(\mathrm{t}), 78.58(\mathrm{~d}), 94.82(\mathrm{~d}), 95.78(\mathrm{~d})$, 103.00 (s), 118.49 (d), 122.03 (d, intense), 127.34 (d, intense), 135.98 (s), 139.24 (s), 150.85 (s), 162.55 (s), 164.06 (s), 167.35 (s), 169.33 (s), 195.44 (s); MS (GC/MS, $70 \mathrm{eV}) \mathrm{m} / z$ (relative intensity): 382 (52) $\left[\mathrm{M}^{+}\right], 340$ (16) [ $\left.\mathrm{M}^{+}-\mathrm{CH}_{2} \mathrm{CO}\right], 339$ (14) [ $\left.\mathrm{M}^{+}-\mathrm{CH}_{3} \mathrm{CO}\right], 165$ (100). Anal. Calcd for $\mathrm{C}_{22} \mathrm{H}_{22} \mathrm{O}_{6}$ : C, 69.10; H, 5.80. Found C, 68.92; H, 5.85 .

\section{Cell Culture}

Acute myeloid leukemia cells (HL-60; DSMZ, Germany) were maintained in RPMI 1640 medium with $10 \%$ heat-inactivated fetal calf serum (Gibco, France). Cells were grown at $37^{\circ} \mathrm{C}$ in a humidified $5 \% \mathrm{CO}_{2}$ atmosphere and maintained at a density of $2 \times 10^{5}$ to $1 \times 10^{6}$ cells $/ \mathrm{ml}$ by resuspending the cells in fresh culture medium every 2 days. Human breast adenocarcinoma cells (MCF-7 cells; DSMZ, Germany) were cultured in Dulbecco's medium without Phenol Red (Biochrom). For experimental analysis the cells were suspended with fresh medium in a centrifuge tube and centrifuged for $5 \mathrm{~min}\left(20^{\circ} \mathrm{C}\right)$ at $115 \mathrm{~g}$. The cell pellet was resuspended in fresh medium and 50,000 cells/well were pipetted into a 96-well plate and left to recover for $24 \mathrm{~h}$ under standard conditions $\left(37^{\circ} \mathrm{C}, 5 \% \mathrm{CO}_{2}\right)$ before they were subjected to the treatments described below.

\section{Toxicity Tests}

Cytotoxicity of the test compounds was determined using a resazurin-based test [20]. The cells were incubated for up to $144 \mathrm{~h}$ in medium containing the test substances at different concentrations ranging from 1 to $50 \mu \mathrm{mol} / 1$. Since the substances were dissolved in DMSO (50 mmol/1 stock), the concentration of DMSO was adjusted to $0.1 \%$ DMSO $(14 \mathrm{mmol} / \mathrm{l})$ in all samples including the control. Resazurin $(0.5 \mathrm{mmol} / \mathrm{l}$ in PBS diluted $1: 10$ with medium $)$ was added, the cells incubated for $3 \mathrm{~h}$ and the fluorescence of the formed resorufin measured (excitation 544, emission $590 \mathrm{~nm}$ ) in a microplate reader (FLUOstar; BMG, Germany).

\section{Effects on Cell Proliferation}

HL-60 cells were stained with carboxyfluorescein succinimidyl ester (CFSE; Molecular Probes, Eugene, Oreg., USA) as described by Lyons [21] and Parish [22]. Cells were incubated at $37^{\circ} \mathrm{C}$ in PBS containing $10 \mu \mathrm{mol} / \mathrm{l} \mathrm{CFSE}$ for $10 \mathrm{~min}$, washed and placed in culture medium (approximately $2 \times 10^{5}$ cells $/ \mathrm{ml}$ ) $1 \mathrm{~h}$ before the exposure to the 4 test compounds 5-O-PN, 6-DMAN, 7-O-PN, 8-PN (5 and $50 \mu \mathrm{mol} / \mathrm{l})$. Since the flavonoid stock solutions were prepared in DMSO, all cultures were made in $0.1 \%$ DMSO $(14 \mathrm{mmol} / \mathrm{l})$ including the control sample. A second control sample with high DMSO content $(1.2 \%$, equivalent to $170 \mathrm{mmol} / \mathrm{l})$ was prepared since under these conditions HL-60 cells differentiate into granulocyte-like cells. The same volume of the suspension cultures were harvested after 1,2 and 4 days, fixed in $70 \%$ ethanol and stored overnight at $-20^{\circ} \mathrm{C}$. The cells were spun down again and the pellet was resuspended in PBS containing 50 $\mu \mathrm{g} / \mathrm{ml}$ propidium iodide (PI) and $0.2 \mathrm{mg} / \mathrm{ml}$ RNase (Sigma, Germany) and incubated for at least $45 \mathrm{~min}$. Between 1 and $5 \times 10^{5}$ cells per sample were analyzed by flow cytometry (CyFlow, Partec, Germany). For each variable (exposure conditions, culture periods, etc.) six samples were quantified. The fraction of cells present in different cell generations and their representation in the respective cell cycle phases were calculated using the CyFlow software.

\section{Antioxidative Effects}

The oxidant menadione (2-methyl-1,4-naphthoquinone) was used to analyze the possible antioxidative activity of the flavonoids. The first test was based on the reaction of oxygen radicals with 2,2diphenyl-1-picrylhydrazyl (DPPH; Fluka, Germany) and the radical scavenging activity of the flavonoids (concentration range 5-80 $\mu \mathrm{mol} / \mathrm{l}$ ) was tested in 96-well microtiter plates (NUNC, Germany) following the protocol of Wang et al. [23]. The absorption was measured at $517 \mathrm{~nm}$ in a microtiter plate reader (Spectra Rainbow, Tecan, Germany).

The (anti)oxidative properties of the test compounds were quantified by flow cytometry. Several fluorescence-based detection systems for different ROS are available and have been used to characterize the antioxidative properties of the flavonoids under study. $2^{\prime}, 7^{\prime}-$ Dichlorodihydrofluorescein diacetate (DCF; Fluka, Germany) is commonly used to detect the generation of reactive oxygen intermediates including hydrogen peroxide and nitric oxide [17, 24]. DCF passively diffuses into the cells, is deacetylated and subsequently oxidized to yield the highly fluorescent $2^{\prime}, 7^{\prime}$-dichlorofluorescein diacetate [25]. Dihydrorhodamine-123 (DHR; Fluka, Germany) also passively diffuses across most cell membranes where it is oxidized to cationic rhodamine- 123 which becomes localized in the mitochondria. DHR does not directly detect superoxide, but rather reacts with hydrogen peroxide in the presence of peroxidase, cytochrome $c$ or $\mathrm{Fe}^{2+}[26]$. However, DHR also reacts with peroxynitrite, the anion formed when nitric oxide reacts with superoxide [27]. Hydroethidine (dihydroethidium (HE); Fluka, Germany) is rapidly oxidized by ROS to yield ethidium which intercalates with the cell's DNA so that bright red nuclei can be visualized in the fluorescence microscope [28]. Although HE is commonly used to analyze respiratory burst in phagocytes, it has been reported that this probe undergoes significant oxidation in resting leukocytes, possibly through the uncoupling of mitochondrial oxidative phosphorylation [29]. 4-Amino-5-methylamino-2',7'-difluorofluorescein diacetate (DAF; Molecular Probes, The Netherlands) is useful to detect nitric oxide production in living cells or solutions. The fluorescence quantum yield of DAF is reported to increase about 160-fold after reacting with $\mathrm{NO}$ [30]. 
The staining procedure was basically carried out as described by [31]. HL-60-cells were incubated in medium containing the flavonoids $(10 \mu \mathrm{mol} / \mathrm{l})$ for $60 \mathrm{~min}$, then treated with the oxidant menadione (final concentration $20 \mu \mathrm{mol} / \mathrm{l}$ ) for $60 \mathrm{~min}$, and incubated in either $10 \mu \mathrm{mol} / 1 \mathrm{DCF}, 5 \mu \mathrm{mol} / 1 \mathrm{DHR}, 5 \mu \mathrm{mol} / 1 \mathrm{HE}$ or $5 \mu \mathrm{mol} / 1 \mathrm{DAF}$ for additional $30 \mathrm{~min}$. The cells were centrifuged again to replace the medium with PBS and the fluorescence was determined by flow cytometry (Cyflow).

\section{Mitochondrial Membrane Potential}

The mitochondria-selective indicator for the membrane potential 5,5',6,6'-tetrachloro-1,1',3,3'-tetraethylbenzimidazolylcarbocyanine iodide (JC-1) was purchased from Molecular Probes (Leiden, The Netherlands). This dye forms at high mitochondrial membrane potential $(\Delta \Psi \mathrm{m}>140 \mathrm{mV})$ characteristic $\mathrm{J}$ aggregates with an emission maximum at $590 \mathrm{~nm}$ [32]. A decrease in $\Delta \Psi \mathrm{m}$ can be monitored as reduction in red fluorescence and an increase in yellow-green JC-1 monomers (emission maximum $527 \mathrm{~nm}$ ). A stock solution of the dye $(3 \mathrm{mmol} / \mathrm{l})$ was prepared in DMSO and the effect of each flavonoid was tested at a concentration of $10 \mu \mathrm{mol} / \mathrm{l}$. Cells were adjusted to a density of 0.5 to $3 \times 10^{6} / \mathrm{ml}$, incubated in medium containing the test substances for $60 \mathrm{~min}$ and stained with JC-1 $(10 \mu \mathrm{mol} / \mathrm{l})$ for additional $30 \mathrm{~min}$ at $37^{\circ} \mathrm{C}$. Cells were washed with PBS and the yellowgreen and red fluorescence quantified by flow cytometry (CyFlow). The effect of the oxidant menadione on the mitochondrial membrane potential was analyzed as positive control.

\section{Statistics}

The experimental data are expressed as the mean \pm SD of several independent experiments (see Results for details). The significance of the recorded effects was assessed by analysis of variance (ANOVA).

\section{Results}

The structures of the chemically synthesized flavonoids 8-PN, 7-O-PN, 5-O-PN and 6-DMAN are illustrated in figure 1 . Based on previous studies using other flavonoids we expected that prenylation and the addition/ reduction of $\mathrm{OH}$ groups would alter the biological activity of the compounds. This expectation turned out to be correct as demonstrated by the various tests employed in this study.

\section{Toxicity}

The toxicity of the compounds was first tested using a general toxicity test based on the reduction of resazurin by metabolically active cells. The advantage of the test is that the fluorescent product resorufin can be quantified in the cell supernatant of the cell culture and the test can be scaled up for high throughput. For comparison we used two different human cell lines: the promyeloid leukemia cell line HL-60 which grows in suspension, and the adherent breast cancer cell line MCF-7. When the cells were

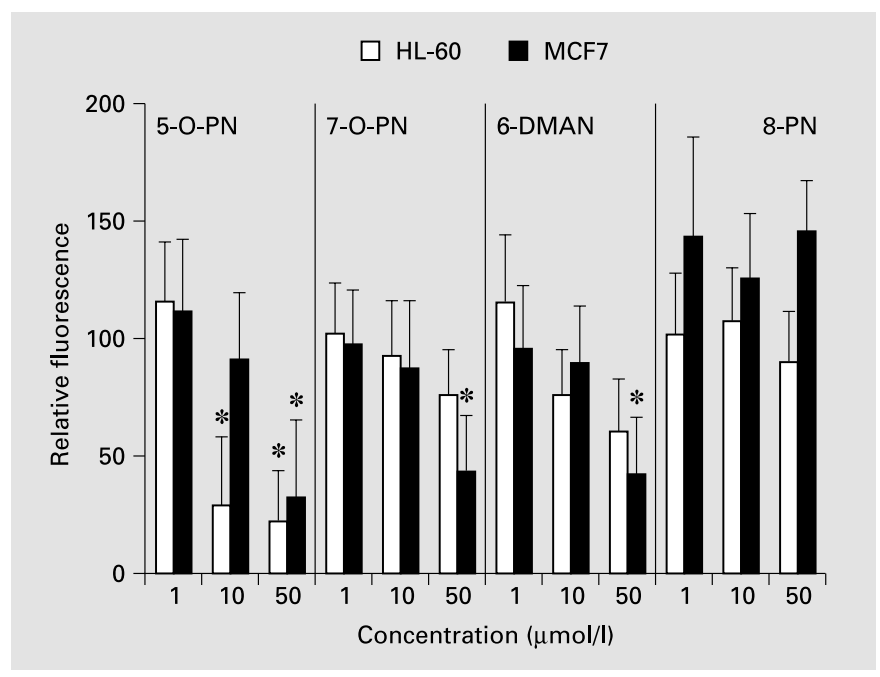

Fig. 2. Toxicity of the tested flavonoids (naringenin derivatives) quantified by the formation of resorufin from resazurin. The human cell lines HL-60 (acute myeloid leukemia) and MCF-7 (breast cancer) were cultured in the presence of the flavonoids at the indicated concentrations for $48 \mathrm{~h}$. Finally, resazurin was added and quantified after $3 \mathrm{~h}$ by determining the fluorescence in the medium. The values of the control samples were set to 100 . The data represent the arithmetic mean \pm SD of 5 separate experiments. * Significant difference $(p<0.05)$ between control and flavonoid-treated cells.

grown in the presence of the different compounds for $48 \mathrm{~h}$, differences became apparent both between the substances and between the two cell lines (fig. 2). 5-O-PN was very toxic for HL-60 cells at $10 \mu \mathrm{mol} / \mathrm{l}$ concentration ( $29 \%$ of control values, $\mathrm{p}<0.05$ ), while a similar toxicity was only reached at $50 \mu \mathrm{mol} / 1$ for MCF-7 cells $(32 \%$, p < $0.05)$. All other substances were less toxic and 6-DMAN and 7-O-PN reduced the resazurin level reproducibly in MCF-7 cells only at the highest concentration tested (50 $\mu \mathrm{mol} / 1 ; \mathrm{p}<0.05)$. 8-PN showed no toxicity in this test ( $\mathrm{p}>$ $0.05)$, but a difference between the two cell lines was apparent at $50 \mu \mathrm{mol} / 1(\mathrm{p}<0.05)$. The experimental conditions (use of normal FCS, i.e. not dextran charcoaltreated) were optimized to study toxicity and not estrogenic effects. Nevertheless, in case of 8-PN the absorption levels were higher for MCF-7 cells compared to HL-60 cells presumably reflecting the fact that 8 -PN is highly estrogenic and MCF-7 cells are estrogen-responsive with respect to cell proliferation.

\section{Cell Cycle Analysis}

In all further experiments we used exclusively HL-60 cells so that possible estrogenic effects could be neglected. 


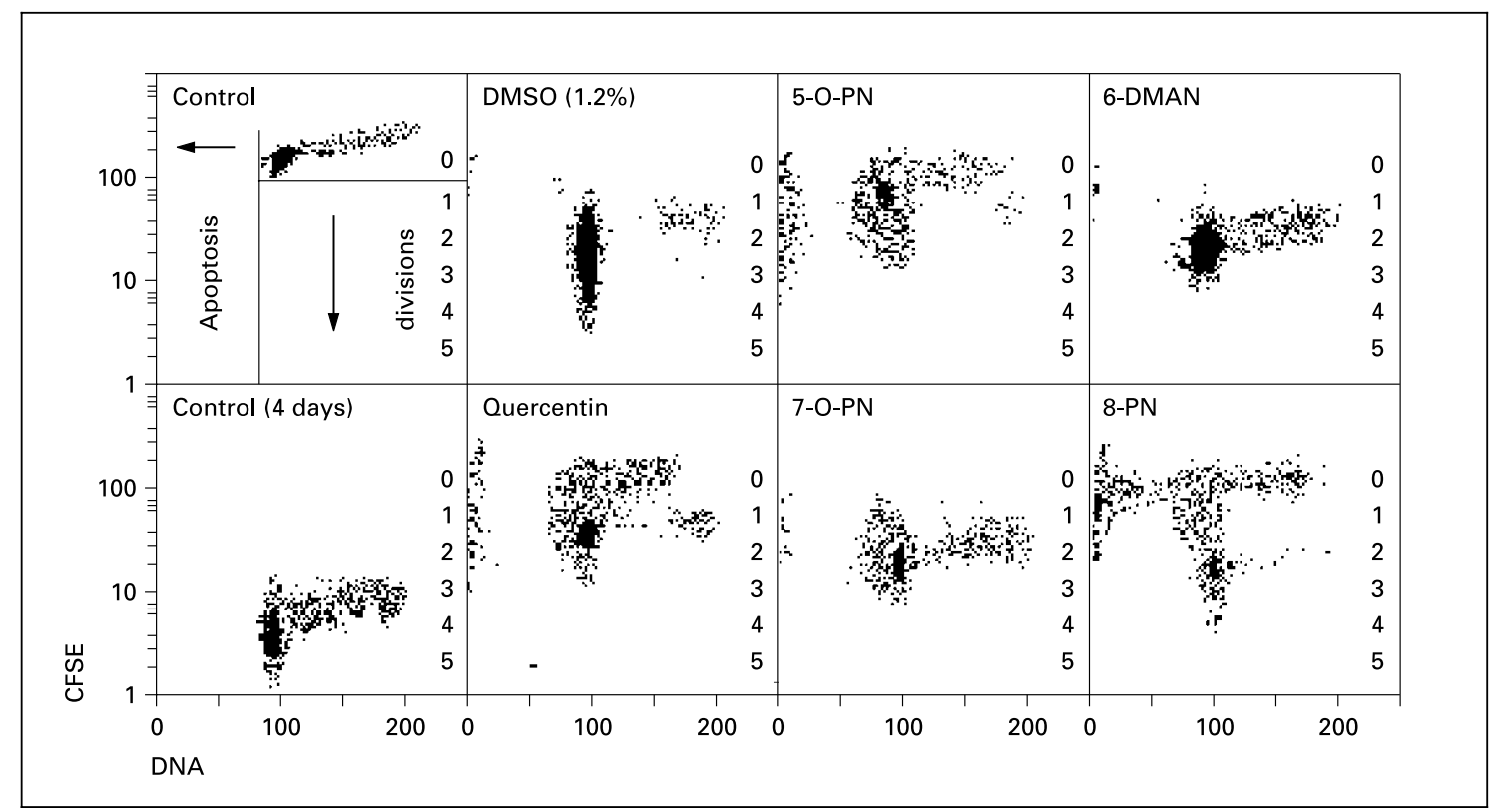

Fig. 3. Effect of flavonoids on cell proliferation. Asynchronously proliferating HL-60 cells were stained with CFSE (defined as division 0) and after $1 \mathrm{~h}$ treated with the indicated flavonoids $(50 \mu \mathrm{mol} / \mathrm{l})$. The solvent DMSO $(0.1 \%)$ was present in flavonoid samples as well as in controls. An additional control culture was exposed to 1.2\% DMSO, a concentration which leads to cell cycle arrest and cell differentiation at the $\mathrm{G}_{0+1}$ phase. After 4 days the cells were stained with PI and the fluorescence analyzed in two-dimensional plots. The different cell generations, labelled 1-5, can be distinguished on the basis of their CFSE content. Cycling and arrested cells can be distinguished and the dynamics of proliferation determined in each sample. Furthermore, the presence of hypodiploid cells and the cell cycle phases can be analyzed in the respective cell generations.
These cells grow in suspension culture and can, therefore, easily be analyzed by flow cytometry. The proliferation was analyzed with the fluorescent stain CFSE which allows the distinction of successive cell generations as well as cell cycle arrested cells due to the fact that the fluorescence is roughly halved at every division [21, 22]. The reduction in CFSE fluorescence after 4 days of culture is illustrated in figure 3. The control population (labelled ' 0 ' division) divides 3-5 times during this period of time. Additional information was obtained by analyzing the DNA content at the end of each experiment so that the distribution of the cells in the respective cell cycle phases and the fraction of hypodiploid cell could be determined in two-dimensional plots.

Quantitative data after 1 and 2 days of incubation are compiled in table 1. In each sample 50,000 cells were analyzed. DMSO $(0.1 \%)$ was added to control cultures since DMSO was used as solvent for the test substances and was present at this concentration in all samples. The addition of such a small amount of DMSO did not significantly affect $(p<0.05)$ the cell cycle distribution or the fraction of apoptotic or arrested cells (data not shown). Since high concentrations of DMSO result in the differentiation of HL-60 cells into granulocyte-like cells [33], we also studied the effects of $1.2 \%$ DMSO on the cell cycle. With respect to apoptosis the effect was small but noticeable $(11 \pm 1 \%$ after $48 \mathrm{~h}$ ). Within 2 days the cells were arrested at the $\mathrm{G}_{0+1}$ phase of the cell cycle as predicted $(83 \pm 2 \%)$ and the effect was also clearly visible in two-dimensional plots after 4 days of culture (fig. 3).

At the highest concentration tested $(50 \mu \mathrm{mol} / \mathrm{l})$, all flavonoids were more or less toxic (table 1) so that after 24hour incubations a substantial fraction of the cells became hypodiploid, the criterion used to identify nonviable (presumably apoptotic) cells (5-O-PN $84 \pm 6 \%$, 6-DMAN $27 \pm 3 \%$, 7-O-PN $54 \pm 3 \%$, 8-PN $12 \pm 2 \%$, Q $26 \pm 4 \%$ ). Lower concentrations $(0.1,5$, and $10 \mu \mathrm{mol} / \mathrm{l})$ showed little or no toxicity with the exception of 5-O-PN. This compound increased the percentage of hypodiploid cells to $34 \pm 2 \%$ at $5 \mu \mathrm{mol} / 1$ concentration. At $50 \mu \mathrm{mol} / 1$ flavonoid concentration, the percentage of cells present in the $\mathrm{G}_{0+1}$ phase of the cell cycle increased to $66 \pm 2 \%$ (6DMAN), $82 \pm 1 \%$ (7-O-PN), $70 \pm 4 \%(8-\mathrm{PN})$ and $49 \pm$ $4 \%(\mathrm{Q})$. The block or lengthening of the $\mathrm{G}_{0+1}$ phase was 
Table 1. Effects of the naringenin derivatives on proliferation of HL-60 cells

\begin{tabular}{|c|c|c|c|c|c|c|c|c|c|c|}
\hline \multirow{3}{*}{$\begin{array}{l}\text { Test } \\
\text { substances }\end{array}$} & \multirow{3}{*}{$\begin{array}{l}\text { Concentration } \\
\mu \mathrm{mol} / 1\end{array}$} & \multicolumn{4}{|c|}{ Exposure for 1 day } & \multicolumn{5}{|c|}{ Exposure for 2 days } \\
\hline & & \multirow[t]{2}{*}{$<2 \mathrm{C}, \%^{1}$} & \multicolumn{3}{|c|}{ cycling cells, $\%^{3}$} & \multirow[t]{2}{*}{$<2 \mathrm{C}, \%^{1}$} & \multirow[t]{2}{*}{ arrested $^{2}$} & \multicolumn{3}{|c|}{ cycling cells, $\%^{3}$} \\
\hline & & & $\mathrm{G}_{0+1}$ & S & $\mathrm{G}_{2}+\mathrm{M}$ & & & $\mathrm{G}_{0+1}$ & $\mathrm{~S}$ & $\mathrm{G}_{2}+\mathrm{M}$ \\
\hline DMSO & $14 \times 10^{3}$ & $5 \pm 2$ & $54 \pm 2$ & $36 \pm 3$ & $10 \pm 2$ & $5 \pm 2$ & $5 \pm 2$ & $55 \pm 4$ & $35 \pm 3$ & $10 \pm 2$ \\
\hline DMSO & $170 \times 10^{3}$ & $9 \pm 3$ & $56 \pm 3$ & $30 \pm 4$ & $14 \pm 3$ & $11 \pm 1$ & $11 \pm 4$ & $83 \pm 2$ & $6 \pm 2$ & $11 \pm 1$ \\
\hline 5-O-PN & 0.1 & $6 \pm 1$ & $52 \pm 2$ & $36 \pm 2$ & $12 \pm 1$ & $5 \pm 1$ & $5 \pm 1$ & $49 \pm 2$ & $38 \pm 1$ & $13 \pm 1$ \\
\hline 5-O-PN & 5.0 & $34 \pm 2$ & $40 \pm 3$ & $53 \pm 5$ & $7 \pm 1$ & $35 \pm 3$ & $34 \pm 2$ & $53 \pm 3$ & $38 \pm 4$ & $9 \pm 1$ \\
\hline 5-O-PN & 10.0 & $39 \pm 3$ & $40 \pm 3$ & $53 \pm 4$ & $7 \pm 1$ & $33 \pm 4$ & $33 \pm 4$ & $47 \pm 5$ & $47 \pm 5$ & $6 \pm 2$ \\
\hline 5-O-PN & 50.0 & $84 \pm 6$ & $39 \pm 3$ & $54 \pm 6$ & $7 \pm 1$ & $35 \pm 5$ & $43 \pm 2$ & $53 \pm 4$ & $34 \pm 4$ & $13 \pm 2$ \\
\hline 6-DMAN & 0.1 & $5 \pm 1$ & $50 \pm 1$ & $37 \pm 2$ & $13 \pm 3$ & $6 \pm 1$ & $5 \pm 2$ & $51 \pm 2$ & $40 \pm 2$ & $9 \pm 1$ \\
\hline 6-DMAN & 5.0 & $6 \pm 2$ & $58 \pm 1$ & $29 \pm 3$ & $13 \pm 1$ & $8 \pm 1$ & $11 \pm 1$ & $56 \pm 2$ & $34 \pm 5$ & $10 \pm 2$ \\
\hline 6-DMAN & 10.0 & $5 \pm 2$ & $58 \pm 2$ & $28 \pm 3$ & $14 \pm 2$ & $7 \pm 1$ & $12 \pm 2$ & $52 \pm 4$ & $39 \pm 5$ & $9 \pm 1$ \\
\hline 6-DMAN & 50.0 & $27 \pm 3$ & $66 \pm 2$ & $22 \pm 3$ & $12 \pm 2$ & $26 \pm 5$ & $13 \pm 2$ & $58 \pm 4$ & $28 \pm 4$ & $14 \pm 2$ \\
\hline 7-O-PN & 0.1 & $5 \pm 2$ & $55 \pm 2$ & $35 \pm 2$ & $10 \pm 2$ & $5 \pm 1$ & $3 \pm 1$ & $55 \pm 2$ & $35 \pm 1$ & $10 \pm 1$ \\
\hline 7-O-PN & 5.0 & $5 \pm 2$ & $50 \pm 2$ & $35 \pm 3$ & $15 \pm 3$ & $7 \pm 1$ & $7 \pm 1$ & $59 \pm 3$ & $30 \pm 4$ & $11 \pm 1$ \\
\hline 7-O-PN & 10.0 & $5 \pm 2$ & $52 \pm 2$ & $33 \pm 2$ & $15 \pm 2$ & $5 \pm 1$ & $6 \pm 3$ & $56 \pm 2$ & $34 \pm 1$ & $10 \pm 1$ \\
\hline 7-O-PN & 50.0 & $54 \pm 3$ & $82 \pm 1$ & $9 \pm 1$ & $9 \pm 2$ & $29 \pm 6$ & $10 \pm 3$ & $64 \pm 4$ & $23 \pm 3$ & $13 \pm 1$ \\
\hline 8-PN & 0.1 & $5 \pm 2$ & $55 \pm 1$ & $33 \pm 2$ & $12 \pm 2$ & $5 \pm 1$ & $2 \pm 1$ & $56 \pm 2$ & $32 \pm 7$ & $12 \pm 1$ \\
\hline 8-PN & 5.0 & $5 \pm 2$ & $53 \pm 2$ & $35 \pm 2$ & $12 \pm 2$ & $7 \pm 1$ & $3 \pm 1$ & $60 \pm 4$ & $30 \pm 5$ & $10 \pm 1$ \\
\hline 8-O-PN & 10.0 & $6 \pm 2$ & $53 \pm 1$ & $34 \pm 2$ & $13 \pm 2$ & $7 \pm 2$ & $6 \pm 2$ & $60 \pm 2$ & $31 \pm 2$ & $9 \pm 1$ \\
\hline 8-PN & 50.0 & $12 \pm 2$ & $70 \pm 4$ & $20 \pm 3$ & $10 \pm 2$ & $16 \pm 2$ & $11 \pm 1$ & $73 \pm 1$ & $17 \pm 2$ & $10 \pm 1$ \\
\hline Quercetin & 10.0 & $21 \pm 5$ & $43 \pm 3$ & $37 \pm 2$ & $20 \pm 2$ & $34 \pm 2$ & $28 \pm 3$ & $47 \pm 4$ & $36 \pm 2$ & $17 \pm 1$ \\
\hline Quercetin & 50.0 & $26 \pm 4$ & $49 \pm 4$ & $37 \pm 2$ & $14 \pm 3$ & $36 \pm 6$ & $31 \pm 3$ & $51 \pm 3$ & $36 \pm 3$ & $13 \pm 2$ \\
\hline
\end{tabular}

The data show the effects of the test substances on the cell cycle of HL-60 cells after exposure for 1 and 2 days (average \pm SD of 6 independent experiments). Statistically significant differences $(\mathrm{p}<0.05)$ to control cultures are indicated in bold print. Since the flavonoids were dissolved in a DMSO stock solution, all cultures (including the control) were made $14 \mathrm{mmol} / 1(0.1 \%)$ in DMSO.

1 The percentage of hypodiploid cells $(<2 \mathrm{C}$ DNA content) was calculated from the total number of cells.

2 The fraction of cell cycle-arrested cells was calculated from the total number of cells.

3 The distribution of cells in different cell cycle phases was calculated (\%) from the population of cycling cells.

not observed in 5-O-PN-treated cells $(39 \pm 3 \%)$ presumably due to the fact that a high percentage of $\mathrm{G}_{0+1}$ cells became apoptotic. None of the four naringenins caused a cell cycle arrest at the $\mathrm{G}_{2}$ phase of the cell cycle, an effect that was apparent in quercetin-treated $(10 \mu \mathrm{mol} / \mathrm{l}) \mathrm{HL}-60$ cells ( $20 \pm 1 \%$ in $\mathrm{G}_{2}$ phase). At $50 \mu \mathrm{mol} / \mathrm{l}$ concentration, the block is less clear presumably because (similar to 5O-PN) the toxic effects partly obscure the cell cycle block (unpublished observation).

On the 2nd day of culture, the percentage of hypodiploid cells tended to decrease presumably because some of the dead cells were degraded and were no longer scored by flow cytometry. However, since most normally proliferating cells have completed the second cell division (and hence possess at most a quarter the amount of CFSE) cell cycle-arrested cells can now be identified and the fraction of affected cells was considerable. The inhibition was particularly strong for 5-O-PN (43 $\pm 2 \%)$ and for 6-DMAN
$(13 \pm 2 \%)$ at $50 \mu \mathrm{mol} / 1$ concentration. The fraction of cells that did cycle (set to $100 \%$ ) was analyzed with respect to the cell cycle phases (table 1). When compared to control cultures, some deviations from the normal cell cycle distribution were apparent. Interestingly, 8-PN tended to prolong the $G_{1}$ phase or to arrest cells in this phase, while quercetin-treated cells showed this effect in $\mathrm{G}_{2}$. The cell cycle distribution of 5-O-PN did not deviate much from the normal distribution presumably reflecting the high toxicity and the initiation of apoptosis particularly at $G_{1}$ and $G_{2}$ of the cell cycle.

When the experiment was extended to 4 days, the untreated (control) culture became heterogeneous with respect to the cell generation; some cells were already in the 5th division, while other cells had completed only 3 or 4 rounds of division (fig. 3). With respect to the flavonoidtreated cultures, the percentage of cycling cells increased. However, the induction of apoptosis and the cell cycle 


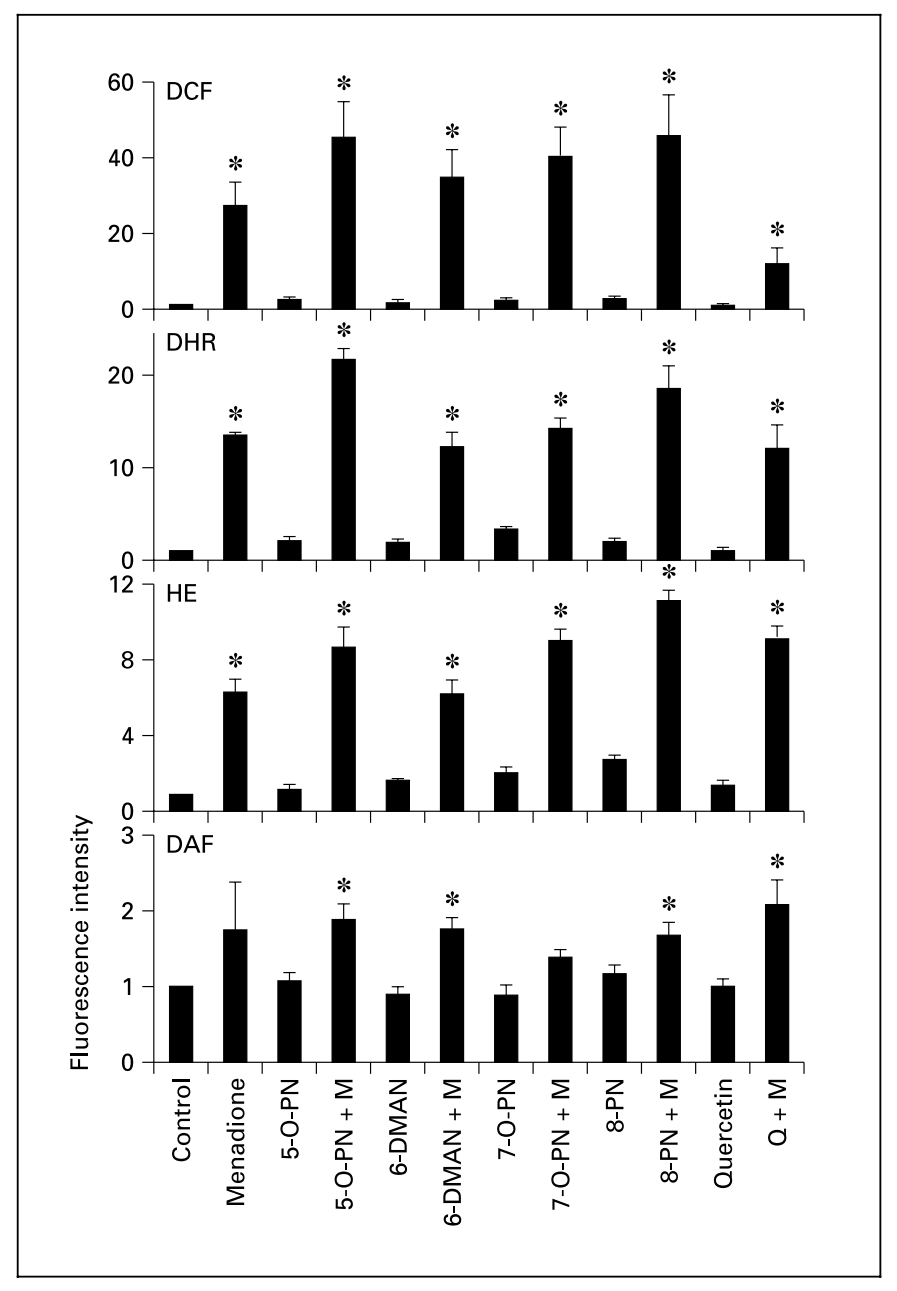

Fig. 4. Four different fluorescent probes (DCF, DHR, HE, DAF) were used to measure the level of reactive oxygen species (ROS) in HL-60 cell cultures. The cells were either treated for $60 \mathrm{~min}$ with the indicated flavonoids only $(10 \mu \mathrm{mol} / \mathrm{l})$ or incubated with $20 \mu \mathrm{mol} / \mathrm{l}$ menadione (M) for $60 \mathrm{~min}$ prior to flavonoid treatment in order to test if the compounds possess antioxidative potential. The fluorescence level in the cultures was determined with reference to the controls $(n=1)$ by flow cytometry. The data represent the arithmetic mean \pm SEM of 3 separate experiments. * Significant difference $(\mathrm{p}<$ 0.05 ) between control and flavonoid-treated cells.

arrest described above were still noticeable in two-dimensional plots representing both CFSE and PI fluorescence (fig. 3). An interesting difference between 8-PN on the one hand and 6-DMAN and 7-O-PN on the other hand became apparent after 4 days that could not be seen after 2 days of culture (table 1). While the cell cycle-arrested cells in the samples treated with 8-PN (or quercetin) never re-entered the cell cycle, the cultures treated with the flavonoids 6-DMAN and 7-O-PN merely slowed down the rate of division, and permanently arrested cells were not visible. In fact, the cells classified as 'arrested' after exposure to 6-DMAN and 7-O-PN (2-day incubations; table 1) may be more correctly described as very slow cycling. During the successive cell divisions and at least up to the 4th cell cycle (fig. 3), some cells became hypodiploid. Cells treated with $1.2 \%$ DMSO became, as expected, arrested at $\mathrm{G}_{1+0}$ due to the induced differentiation (see above).

\section{Radical Scavenger Activity}

Because of the medically relevant antioxidative property of many flavonoids, we studied the ROS scavenging activity of the naringenin derivatives and included quercetin as positive control. Quercetin is a known scavenger of hydroxyl, peroxyl and superoxide radicals [34-36]. A first indication of the scavenger activity is conveniently provided by the DPPH test. As expected, quercetin acted as an efficient ROS scavenger in this test (reduction by $37 \%$ at $100 \mu \mathrm{mol} / 1$ concentration, $\mathrm{p}<0.05$ ). However, using the same experimental protocol, none of the naringenin derivatives gave a significant reaction $(p>0.05)$.

In a second series of experiments we used the cell permeant indicators DCF, DHR, HE and DAF (see Materials and Methods for details) which after their reaction with ROS become fluorescent and their level in the cell can be quantified by flow cytometry. The mean intensity of control cells was set to 1 and deviation in the experimental samples calculated with reference to the control. The data obtained with the selected flavonoids and the oxidative stressor menadione (alone or in combination with the flavonoids) are shown in the figure 4 . Menadione participates in oxidative cycling, which predominantly generates superoxide and more ROS by depletion of sulfhydryl groups [37]. Menadione alone $(20 \mu \mathrm{mol} / \mathrm{l})$ increased the level of fluorescence in all test systems, but the increase with reference to the control $(=1)$ was, as expected, quite different for the different indicator molecules and amounted to $28 \pm 5$ (DCF, p < 0.05), $13.7 \pm$ 0.1 (DHR, p<0.05), $6.3 \pm 0.6$ (HE, p < 0.05), and $1.8 \pm$ 0.6 (DAF, $\mathrm{p}>0.05$ ).

Exposure of HL-60 cells to quercetin $(10 \mu \mathrm{mol} / \mathrm{l})$ for 60 min reduced the DCF fluorescence in controls significantly to $0.7 \pm 0.1(\mathrm{p}<0.05)$, an effect which was not observed using the other fluorescent ROS indicator substances (DHR 0.9 \pm 0.1 , HE $1.4 \pm 0.2$, and DAF $1.0 \pm$ $0.1 ; \mathrm{p}>0.05)$. If the cells were treated with quercetin $(10 \mu \mathrm{mol} / \mathrm{l})$ prior to menadione $(20 \mu \mathrm{mol} / \mathrm{l})$, the DCF fluorescence was significant $(12.0 \pm 4, \mathrm{p}<0.05)$ but lower $(\mathrm{p}<0.05)$ than it was after treatment with menadione alone $(28 \pm 5)$, thus reflecting the antioxidative proper- 
Fig. 5. The mitochondrial membrane potential $(\Delta \Psi \mathrm{m})$ was assayed with the dye JC-1 which fluoresces green when the mitochondrial membranes are normally polarized and red at low potential. a In two-dimensional plots the differences between control cells (C, high potential) and cells treated with $20 \mu \mathrm{mol} / \mathrm{l}$ menadione (M, low potential) are apparent. Similarly, quercetin $(\mathrm{Q}, 10 \mu \mathrm{mol} / \mathrm{l})$ lowers the potential, while 8-PN $(10 \mu \mathrm{mol} / \mathrm{l})$ does not. The percentage of cells present in the respective quadrants is indicated. b Quantitative data on the induced effects on the mitochondrial membrane potential were calculated by the intensity ratio of red to green fluorescence $($ control $=100)$. The data represent the arithmetic mean \pm SEM of three separate experiments. ${ }^{*}$ Significant difference $(p<0.05)$ between control and flavonoid-treated cells.

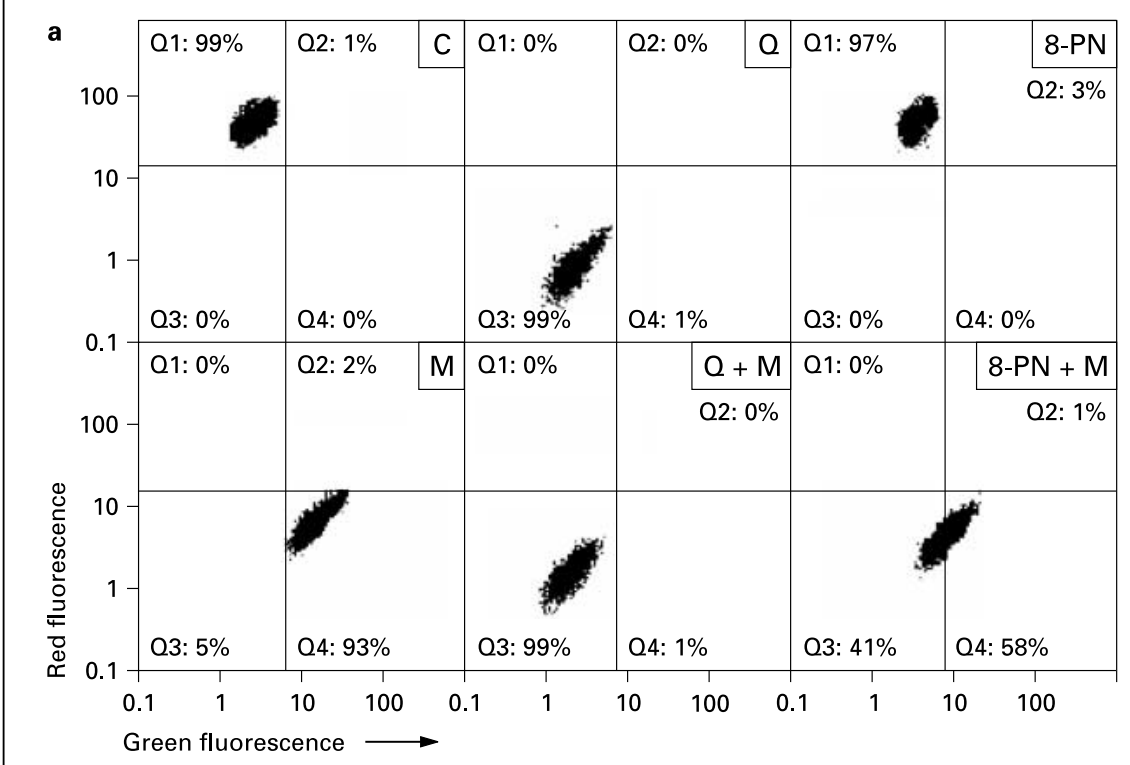

b

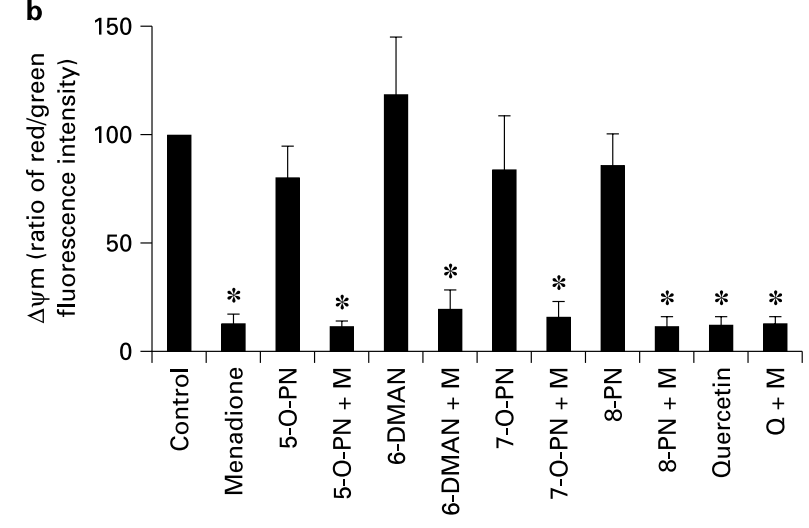

ties of quercetin. However, none of the other indicator substances showed this effect, indicating the different specificity of these indicators. The naringenin derivatives did not lower menadione-induced fluorescence levels and hence did not show an antioxidative activity in any of the applied test systems. To the contrary, a weak oxidative potential for 7-PN and 8-PN was noticed in some experimental test systems when the substances were tested alone or in combination with menadione (fig. 4).

Reduction in Mitochondrial Transmembrane Potential Changes in the mitochondrial membrane potential $(\Delta \Psi \mathrm{m})$ can be reliably measured using the fluorescent indicator dye JC-1. A drop in the potential results in attenuated or abolished ATP production [38] and can, in some cases, indicate the initiation of an apoptotic process. In a series of experiments we treated HL-60 cells with each of the selected flavonoids alone $(10 \mu \mathrm{mol} / \mathrm{l})$ and, in addition, in the presence of oxidative stress induced by menadione $(20 \mu \mathrm{mol} / \mathrm{l})$. For each sample 50,000 cells were stained with JC-1, and analyzed by flow cytometry. While a high membrane potential results in red fluorescence, a shift to green fluorescence is observed as the potential drops (see Materials and Methods).

A clear decrease in the mitochondrial membrane potential was measured in cells stressed with menadione since almost all cells were found in the lower two quadrants $(\mathrm{Q} 3+\mathrm{Q} 4=98 \%)$ as illustrated in figure 5a. The same shift was found in menadione-treated samples which were also exposed to a naringenin derivative 
(shown only for 8-PN). None of the naringenins alone decreased the mitochondrial membrane potential so that the cells stained red and were located in the first quadrant in two-dimensional plots like the cells of the controls (8PN Q1 = 99\% and controls Q1 = 99\%). However, quercetin strongly reduced the membrane potential and this was also observed in cells stressed with both quercetin and menadione.

The membrane potential $\Delta \Psi \mathrm{m}$ was quantified by calculating the ratio of the fluorescence intensity distributions of red to green fluorescence (fig. 5b). The control value was set to 100 . None of the naringenin derivatives had a strong effect on the mitochondrial membrane potential $(\mathrm{p}>0.05)$ in contrast to quercetin $(12 \pm 3, \mathrm{p}<$ $0.05)$. Menadione was effective alone $(13 \pm 4, \mathrm{p}<0.05)$ and in combination with all test substances $(\mathrm{p}<0.05)$. Apparently the strong radical scavenging activity of quercetin (see above) did not protect from menadioneinduced drop of $\Delta \Psi \mathrm{m}$.

\section{Discussion}

The wide spectrum of different biological activities that have been described for flavonoids and the large number of compounds that have been identified in plants make flavonoids an ideal group of substances for studies relating structural properties to specific biological functions on known molecular targets. The possibility to chemically synthesize flavonoids offers new possibilities to study desirable or non-desirable biological effects of specific substitutions of the basic flavonoid structure. For example, it will be possible to remove unwanted (toxic) groups and to select particularly effective groups for the property desired (e.g. estrogenicity or inhibition of certain enzymes). While naringenin and 8-PN have been subject to several studies, the biological properties of the other 3 synthetically produced compounds (7-O-PN, 5-O-PN, 6DMAN) are largely unknown. We have studied the biological properties of these compounds using the well-studied flavonol quercetin as a reference substance. Several tests were employed that give information on the general properties of the test substances and allow quantification of the effects on cell proliferation, energy production and cell survival.

The studied naringenin derivatives showed little toxicity with the exception of the synthetic 5-O-PN. This property is presumably due to the prenylation at position 5 and the concomitant loss of a hydroxyl group. The hydroxyl group of the A-ring seems to be important for the biologi- cal properties of prenylated flavonoids since 7-O PN showed much reduced toxicity in all test systems employed (fig. 1). Short of induced apoptosis, the less severe cellular reactions typically involve cell cycle arrest. The cytostatic properties of several flavonoids have been the subject of many studies. For example, the efficiency of 28 naturally occurring and synthetic flavonoids to inhibit cell proliferation of HL-60 cells was studied [39]. Miranda et al. [5] reported the anti-proliferative and cytotoxic effects of several of prenylated hop flavonoids on human cancer cell lines. The synthetic naringenin derivatives analyzed in the present study also showed anti-proliferative activity at least at the highest concentrations tested $(50 \mu \mathrm{mol} / \mathrm{l})$. At this concentration the hypodiploid cell subpopulation increased in all cultures but to very different degrees. The most toxic substance 5-O-PN induced apoptosis during the first day of exposure particularly at the $G_{1}$ and $G_{2}$ stage of the cell cycle and this effect was noticeable even at $5 \mu \mathrm{mol} / 1$.

The cellular proliferation dynamics can be monitored by CFSE labelling (fig. 3). The different effects of the four compounds suggest that there are quantitative or qualitative differences between the target molecule(s) for each substance. While 6-DMAN and 7-O-PN led to a general slow-down of cell proliferation, the other compounds revealed that the exposed cells may react differently. For example, in case of 8-PN some cells do not cycle after exposure and do not re-enter the cell cycle (and finally undergo apoptosis), while another cell population appears to show little effect. The reason for the different behavior is not clear. Concentration differences in the cells may account for the differences, but alternative explanations must be considered when asynchronously cycling HL-60 cells are stressed by a physical stressor (heat shock) and hence are exposed to exactly the same stress, also cycling and cell cycle-arrested cell populations can be distinguished [40]. Further experiments using synchronized cell cultures are required to test if sensitive phases of the cell cycle may account for the observed effects.

The interaction of quercetin with planar lipid bilayers has been studied in some detail [41]. Quercetin as well as naringenin [42] have an affinity for the hydrophobic membranes and some of their biological activities may be explained by this interaction. Lowering of the $\mathrm{pH}$ favors the lipophilic nature of, for example, naringenin [42]. Flavonoids may affect the membrane potential and, furthermore, produce stress in the bilayer packing thus changing barrier functions. The interactions of flavonoids with the membrane interface seems to be governed partly by the number of hydroxyl groups [for critical discussion, see 
43]. Flavonoids with more hydroxyl groups show stronger interactions with each other and the lipid bilayer. Our test substances possess few hydroxyl groups, but acyl or prenyl side chains instead. From these and many other studies the picture emerges that the biological effects of flavonoids are a to large extent governed by the degree of hydrophobicity and the radical scavenger activity.

The concentration of oxygen and ROS in cells and tissues is tightly controlled. An excess of ROS is toxic and hence ROS production by menadione induces oxidative stress in the exposed cells. These ROS inside cells are believed to be formed through the one-electron reduction of quinones to semiquinone radicals which can rapidly reduce dioxygen to form superoxide anion radical and, subsequently, hydrogen peroxide, hydroxyl radical, and singlet oxygen by dismutation of the superoxide anion radical [44]. Exposing these cells to menadione the antioxidative potential of flavonoids can be tested. Quercetin, for example, is a scavenger of $\mathrm{O}_{2}^{-}, \mathrm{NO}^{*}, \mathrm{HO}^{*}$, peroxy radicals and thus reduces the effect of ROS [31]. To study the antioxidative potential of the 4 flavanones, HL-60 cells were loaded with ROS-sensitive dyes DCF, DHR, HE and DAF. These dyes are effective indicators of different spectra of reactive oxygen (or nitrogen) species and have been widely used to monitor changes in the ROS level within cell cultures including following treatment with plant extracts and certain natural compounds [29, 31, 45]. The tested flavanones were shown to be ineffective as ROS scavengers as compared to the flavonol quercetin.

Several structural features of flavonoids determine their antioxidant properties and among the identified structural properties most relevant for the present discussion are: (i) an $\mathrm{OH}$ group in position 3 of the $\mathrm{C}$-ring; (ii) a double bond at position $\mathrm{C} 2-\mathrm{C} 3$, and (iii) the number of $\mathrm{OH}$ groups substituted on the B-ring, especially in position C-3' [46]. While quercetin possesses most of these properties, the naringenin derivatives do not. Among the tested flavonoids the number of $\mathrm{OH}$ groups varied in a wide range: quercetin has most $\mathrm{OH}$ groups $(\mathrm{n}=5)$, while 5-O-PN has no hydroxyl group at all. If the strong hydrophobicity of 5-O-PN is the reason for the strong toxicity remains to be studied.

The mitochondrial membrane potential is produced by the proton pump and a reduction in the potential indicates attenuated or abolished ATP production. The potential loss can be temporary and may occur spontaneously [47]. In some cases the potential loss may indicate an early step in the apoptotic pathway. Flavonoids were reported to interfere with the energy generation inhibiting the electron transport system. The flavonol quercetin, for example, inhibited NADH oxidase activity while the flavanone naringenin at the same concentration had little inhibitory effect [48]. These and additional data led the authors to suggest that the 2,3 double bond is important for flavonol inhibition of NADH oxidase. Additional hydroxylation in the B-ring to yield a pyrogallol structure further increases the inhibitory activity. Quercetin is also an inhibitor of mitochondrial ATPase [49], while naringenin is not [48]. These reports offer an explanation for the observed decreased mitochondrial membrane potential in quercetin-treated cells as well as a rational for the lack of effects in cells exposed to the naringenin derivatives.

\section{Acknowledgements}

The radical scavenger experiments were in part carried out during a practical course with the students, Katrin Herbst and Angela Daniel. We acknowledge their experimental contribution and shared enthusiasm for the project. Dr. G. Rusak's support during part of the project is also gratefully acknowledged.

\section{References}

1 Milligan SR, Kalita JC, Pocock V, van de Kauter V, Stevens JF, Deinzer ML, Rong H, de Keukeleire D: The endocrine activities of 8prenylnaringenin and related hop (Humulus lupulus L.) flavonoids. J Clin Endorinol Metab 2000;85:4912-4915.

2 Zierau O, Gester S, Schwab P, Metz P, Kolba S, Wulf M, Vollmer G: Estrogenic activity of the phytoestrogens naringenin, 6-(1,1-dimethylallyl)naringenin and 8-prenylnaringenin. Planta Med 2002;68:449-451.
3 Verzele M: 100 years of hop chemistry and its relevance to brewing. J Inst Brew 1986;92:3248.

4 Gester S, Metz P, Zierau O, Vollmer G: An efficient synthesis of the potent phytoestrogen 8prenylnaringenin and 6-(1,1-dimethylallyl)naringenin by europium(III)-catalyzed claisen rearrangement. Tetrahedron 2001;47:10151018.
5 Miranda CL, Stevens JF, Helmrich A, Henderson MC, Rodriguez RJ, Yang YH, Deinzer ML, Barnes DW, Buhler DR: Antiproliferative and cytotoxic effects of prenylated flavonoids from hops (Humulus lupulus) in human cancer cell lines. Food Chem Toxicol 1999;37:271285.

6 Henderson MC, Miranda CL, Stevens JF, Deinzer ML, Buhler DR: In-vitro inhibition of human P450 enzymes by prenylated flavonoids from hops, Humulus lupulus. Xenobiotica 2000;30:235-251. 
7 Kao YC, Zhou C, Sherman M, Laughton CA, Chen S: Molecular basis of the inhibition of human aromatase (estrogen synthetase) by flavone and isoflavone phytoestrogens: A sitedirected mutagenesis study. Environ Health Perspect 1998;106:85-92.

8 Rice-Evans C: Flavonoid antioxidants. Curr Med Chem 2001;8:797-807.

9 Cotelle N: Role of flavonoids in oxidative stress. Curr Top Med Chem 2001;1:569-590.

10 Heijnen CG, Haenen GR, van Acker FA, van der Vijgh WJ, Bast A: Flavonoids as peroxynitrite scavengers: The role of the hydroxyl groups. Toxicol In Vitro 2001;15:3-6.

11 Furuno K, Akasako T, Sugihara N: The contribution of the pyrogallol moiety to the superoxide radical scavenging activity of flavonoids. Biol Pharm Bull 2002;25:19-23.

12 Choi JS, Chung HY, Kang SS, Jung MJ, Kim JW, No JK, Jung HA: The structure-activity relationship of flavonoids as scavengers of peroxynitrite. Phytother Res 2002;16:232-235.

13 Casagrande F, Darbon JM: Effects of structurally related flavonoids on cell cycle progression of human melanoma cells: Regulation of cyclin-dependent kinases CDK2 and CDK1. Biochem Pharmacol 2001;61:1205-1215.

14 Knowles LM, Zigrossi DA, Tauber RA, Hightower C, Milner JA: Flavonoids suppress androgen-independent human prostate tumor proliferation. Nutr Cancer 2000;38:116-122.

15 Matsuyama S, Reed JC: Mitochondria-dependent apoptosis and cellular $\mathrm{pH}$ regulation. Cell Death Differ 2000; 7:1155-1165.

16 Herr I, Debatin KM: Cellular stress response and apoptosis in cancer therapy. Blood 2001; 98:2603-2613.

17 Yasugi E, Uemura I, Kumagai T, Nishikawa Y, Yasugi S, Yuo A: Disruption of mitochondria is an early event during dolichyl monophosphate-induced apoptosis in U937 cells. Zoolog Sci 2002; 19:7-13.

18 Petit PX, Lecoeur H, Zorn E, Dauguet C, Mignotte $\mathrm{B}$, Gougeon ML: Alterations in mitochondrial structure and function are early events of dexamethasone-induced thymocyte apoptosis. J Cell Biol 1995;130:157-167.

19 Rego AC, Vesce S, Nicholls DG: The mechanism of mitochondrial membrane potential retention following release of cytochrome $\mathrm{c}$ in apoptotic GT1-7 neural cells. Cell Death Differ 2001;8:995-1003.

20 O'Brien J, Wilson I, Orton T, Pognan F: Investigation of the Alamar Blue (resazurin) fluorescent dye for the assessment of mammalian cell toxicity. Eur J Biochem 2000;267:5421-5426.

21 Lyons AB: Divided we stand: Tracking cell proliferation with carboxyfluorescein diacetate succinimidyl ester. Immunol Cell Biol 1999;77: 509-515.

22 Parish CR: Fluorescent dyes for lymphocyte migration and proliferation studies. Immunol Cell Biol 1999;77:499-508.
23 Wang S-Y, Kuo Y-H, Chang H-N, Kang P-L, Tsay H-S, Lin K-F, Yang N-S, Shyur L-F: Profiling and characterization antioxidant activities in Anoectochilus formosanus Hayata. J Agric Food Chem 2002;50:1859-1865.

24 Rao KM, Padmanabhan J, Kilby DL, Cohen HJ, Currie MS, Weinberg JB: Flow cytometric analysis of nitric oxide production in human neutrophils using dichlorofluorescein diacetate in the presence of a calmodulin inhibitor. $\mathrm{J}$ Leukoc Biol 1992;51:496-500.

25 LeBel CR, Ischiropoulos H, Bondy CS: Evaluation of the probe $2^{\prime}, 7^{\prime}$-dichlorofluorescin as an indicator of reactive oxygen species formation and oxidative stress. Chem Res Toxicol 1992; $5: 227-231$

26 Royall JA, Ischiropoulos H: Evaluation of 2', 7'dichlorofluorescin and dihydrorhodamine 123 as fluorescent probes for intracellular $\mathrm{H}_{2} \mathrm{O}_{2}$ in cultured endothelial cells. Arch Biochem Biophys 1993;302:348-355.

27 Crow JP, Beckman JS, McCord JM: Sensitivity of the essential zinc-thiolate moiety of yeast alcohol dehydrogenase to hypochlorite and peroxynitrite. Biochemistry 1995;34:3544-3552.

28 Carter WO, Narayanan PK, Robinson JP: Intracellular hydrogen peroxide and superoxide anion detection in endothelial cells. J Leukoc Biol 1994;55:253-258.

29 Rothe G, Valet G: Flow cytometric analysis of respiratory burst activity in phagocytes with hydroethidine and 2',7'-dichlorofluorescin. J Leukoc Biol 1990;47:440-448.

30 Kojima H, Urano Y, Kikuchi K, Higuchi T, Hirata Y, Nagano T: Fluorescent indicators for imaging nitric oxide production. Angew Chem Int Ed Engl 1999;38:3209-3212.

31 Bestwick CS, Milne L: Quercetin modifies reactive oxygen levels but exerts only partial protection against oxidative stress within HL60 cells. Biochim Biophys Acta 2001;1528:4959

32 Smiley ST, Reers M, Mottola-Hartshorn C, Lin M, Chen A, Smith TW, Steele GB, Chen J, Chen LB: Intracellular heterogeneity in mitochondrial membrane potentials revealed by a J-aggregate-forming lipophilic cation JC-1. Proc Natl Acad Sci USA 1991;88:3671-3675.

33 Koeffler HP: Induction of differentiation of human acute myelogenous leukemia cells: Therapeutic implications. Blood 1983;62:709_ 721.

34 Torel J, Cillard J, Cillard P: Antioxydant activity of flavonoids and reactivity with peroxy radicals. Phytochemistry 1986;25:383-385.

35 Morel I, Lescoat G, Cogrel P, Sergent O, Pasdeloup N, Brissot P, Cillard P, Cillard J: Antioxidant and iron-chelating activities of the flavonoids catechin, quercetin and diosmetin on iron-loaded rat hepatocyte cultures. Biochem Pharmacol 1993;45:13-19.
36 Chen Y, Zheng R, Jia Z: Flavonoids as superoxide scavengers and antioxidants. Free Radic Biol Med 1990;9:19-21.

37 Gao X, Dinkova-Kostova AT, Talalay P: Powerful and prolonged protection of human retinal pigment epithelial cells, keratinocytes, and mouse leukemia cells against oxidative damage: The indirect antioxidant effects of sulforaphane. Proc Natl Acad Sci USA 2001;98: 15221-15226.

38 Komarova SV, Ataullakhanov FI, Globus RK: Bioenergetics and mitochondrial transmembrane potential during differentiation of cultured osteoblasts. Am J Physiol Cell Physiol 2000;279:1220-1229.

39 Hirano T, Gotoh M, Oka K: Natural flavonoids and lignans are potent cytostatic agents against human leukemic HL-60 cells. Life Sci 1994;55:1061-1069.

40 Tokalov SV, Gutzeit HO: The heat shock induced cell cycle arrest is attenuated by weak electromagnetic fields. Cell Prolif 2003;36: 101-111.

41 Movileanu L, Neagoe I, Flonta ML: Interaction of the antioxidant flavonoid quercetin with planar lipid bilayers. Int J Pharm 2000;205:135146

42 Recourt K, van Brussel AA, Driessen AJ, Lugtenberg BJ: Accumulation of a nod gene inducer, the flavonoid naringenin, in the cytoplasmic membrane of Rhizobium leguminosarum biovar viciae is caused by the $\mathrm{pH}$-dependent hydrophobicity of naringenin. J Bacteriol 1989; 171:4370-4377.

43 Ollila F, Halling K, Vuorela P, Vuorela H, Slotte JP: Characterization of flavonoid-biomembrane interactions. Arch Biochem Biophys 2002;399:103-108.

44 Thor H, Smith MT, Hartzell P, Bellomo G, Jewell SA, Orrenius S: The metabolism of menadione (2-methyl-1,4-naphthoquinone) by isolated hepatocytes. A study of the implications of oxidative stress in intact cells. J Biol Chem 1982;257:12419-12425.

45 Wie ZH, Peng QL, Lau BHS: Pycnogenol enhances endothelial cell antioxidant defenses. Redox Rep 1997;3:219-224.

46 Cook NC, Samman S: Flavonoids - Chemistry, metabolism, cardioprotective effects, and dietary sources. Nutr Biochem 1996;7:66-76.

47 Buckman JF, Reynolds IJ: Spontaneous changes in mitochondrial membrane potential in cultured neurons. J Neurosci 2001;21:50545065.

48 Bohmont C, Aaronson LM, Mann K, Pardini RS: Inhibition of mitochondrial NADH oxidase, succinoxidase, and ATPase by naturally occurring flavonoids. J Nat Prod 1987;50:427433.

49 Zheng J, Ramirez VD: Inhibition of mitochondrial proton F0F1-ATPase/ATP synthase by polyphenolic phytochemicals. Br J Pharmacol 2000;130:1115-1123. 